\title{
Design of 3 kW Grid-Connected PV Inverter without Transformer
}

\author{
Byunggyu Yu \\ Division of Electrical, Electronic and Control Engineering, Kongju National University, \\ Kongju, Republic of Korea
}

\begin{abstract}
This study presents the design of $3 \mathrm{~kW}$ grid-connected PV inverter using boost converter to increase PV voltage instead of a transformer. Specifically, the key control methods for boost converter and full bridge inverter are presented. In addition, the PLL technology by using all pass filter is presented. In order to verify the feasibility of the presented $3 \mathrm{~kW}$ PV inverter design, experimental results were presented such as Maximum Power Point Tracking (MPPT) function and power factor control. According to the experimental results, the designed PV inverter shows high performances such as 95\% MPPT efficiency and 0.99 power factor. The presented design methodology could be extended to higher power PV application.
\end{abstract}

Key words: PV inverter, PV generation, boost converter, full bridge inverter, control algorithm, power factor

\section{INTRODUCTION}

Grid interactive PV system has the fastest growing rate in the world PV market and has started to play the dominant role (Vithayasrichareon et al., 2015). A PV inverter has to fulfill two main functions in order to feed energy from a PV array into the utility grid: firstly, the inverter should shape the current into a sinusoidal $\mathrm{AC}$ waveform and then the PV array voltage has to be boosted if PV array voltage is lower than the grid voltage (Li et al., 2015; Deshpande and Bhasme, 2017; Noor et al., 2013; Variath et al., 2010). The voltage amplification can be implemented as transformer or boost converter. To date, there are three widely used arrangements for grid interactive PV inverter topologies based on the transformer as shown in Fig. 1 (Kjaer et al., 2005; Xue et al., 2004). The line frequency transformer has the highest safety function than the others but it is regarded as a poor component due to increased size, weight and price (Papanikolaou et al., 2015; Tian et al., 2006). Thus, the transformer-less PV inverters which use boost converter for voltage boosting has been used widely for small power application due to its high efficiency and low cost. In addition, PV inverter using the high frequency transformer has been paid attention in the PV market because it has competitive high efficiency and low cost with galvanic isolation rather than transformer-less type (Kafle et al., 2017).

This study presents the design of $3 \mathrm{~kW}$ grid-connected PV inverter using boost converter to increase PV voltage instead of transformer. As a single-phase PV inverter, the transformer-less PV inverter consists of a boost converter, followed by a Voltage-Source Inverter (VSI). A Digital Signal Processor (DSP) is used as the main controller. The boost converter

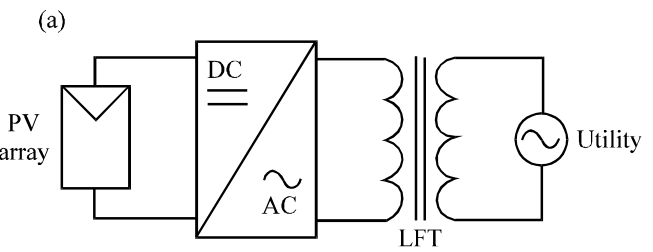

(b)
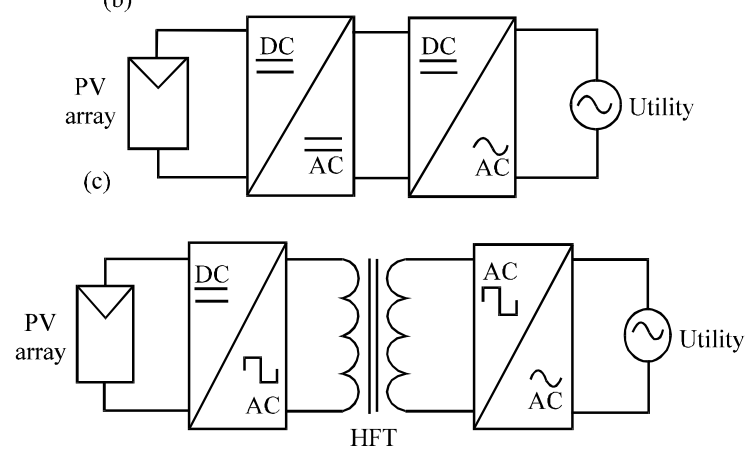

Fig. 1: PV inverter topology classification based on transformer: a) Low frequency transformer; b) Transformer-less and c) High frequency transformer

provides Maximum Power Point Tracking (MPPT) function and the voltage source inverter makes a stable DC link voltage from an unregulated output voltage of PV array.

\section{MATERIALS AND METHODS}

System configuration: As discussed in introduction, the transformer-less PV inverter is implemented using a boost converter, followed by a voltage-source full-bridge inverter shown as in Fig. 2. The boost converter is 
functioning for Maximum Power Point Tracking (MPPT) from PV array and the full bridge Pulse Width Modulation (PWM) inverter makes the regulated DC link voltage of boost converter and sinusoidal $\mathrm{AC}$ waveform in phase with utility voltage.

\section{Design of $3 \mathrm{~kW}$ PV inverter}

Boost converter: As shown in Fig. 3, the MPPT takes measurement of PV voltage and current and then tracking algorithm calculates the reference inductor current $\mathrm{I}_{\mathrm{cov}_{-} \text {ref }}$ where the current should move next. The task of MPPT algorithm is to set $I_{\text {cov_ef }}$ only and it is repeated periodically. Then, there is another control loop that the Proportional and Integral (PI) controller regulates the inductor current. Its task is to minimize error between $\mathrm{I}_{\text {cov_ref }}$ and the measured current $I_{\text {cov } \_p \text { f }}$ by adjusting the duty cycle. The PI loop operates with a much faster rate and provides fast response and overall system stability. The PI controller is implemented with DSP-based controller. The PI controller design for the boost converter is explained as follows. In the boost converter, the switch voltage equation is expressed as:

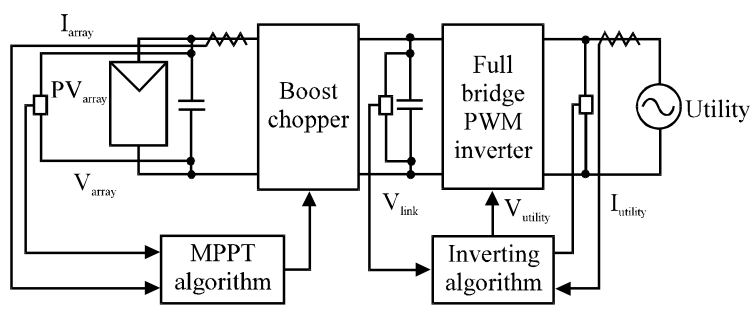

Fig. 2: The implemented PV power conditioning system for single phase

$$
\mathrm{V}_{\mathrm{a}}=\mathrm{V}_{\mathrm{pv}}+\mathrm{L}_{1} \frac{\mathrm{di}_{\mathrm{cov}}}{\mathrm{dt}}
$$

Where:

$\mathrm{V}_{\mathrm{a}}=\mathrm{A}$ DC compensate of voltage across the IGBT

$\mathrm{V}_{\mathrm{pv}}=$ The $\mathrm{PV}$ terminal voltage

$I_{\text {cov }}=$ The converter inductor current

The boost converter transfer function can be derived from the block diagram in Fig. 4. The desired amplitude of the Inductor current $I_{\text {cov_ef }}$ is generated by the MPPT algorithm. The measurement of the inductor current $I_{\text {cov }}$ is used to implement the DC current control loop. The inverter is controlled on the basis of the instantaneous current error $\Delta \mathrm{I}_{\text {cov }}=\mathrm{I}_{\text {cov _efe }} \mathrm{I}_{\text {cov }}$ through a conventional PI current regulator. Therefore, the following expression can be derived from the block diagram represented in Fig. 4:

$$
I_{\text {cov }}=\left(I_{\text {cov_ } \_ \text {ref }}-I_{\text {cov }}\right)\left(\mathrm{K}_{\mathrm{pc}}+\frac{\mathrm{K}_{\mathrm{ic}}}{\mathrm{s}}\right) * \frac{1}{\mathrm{~L}_{1} \mathrm{~s}}
$$

By separating the variables:

$$
\mathrm{I}_{\mathrm{cov}}\left(1+\left(\mathrm{K}_{\mathrm{pc}}+\frac{\mathrm{K}_{\mathrm{ic}}}{\mathrm{s}}\right) * \frac{1}{\mathrm{~L}_{1} \mathrm{~s}}\right)=\left(\mathrm{K}_{\mathrm{pc}}+\frac{\mathrm{K}_{\mathrm{ic}}}{\mathrm{s}}\right) * \frac{1}{\mathrm{~L}_{1} \mathrm{~s}} \mathrm{I}_{\mathrm{cov}-\mathrm{ref}}
$$

And the output transfer function:

$$
\frac{I_{\text {cov }}}{I_{c o v-r e f}}=\frac{\left(\mathrm{K}_{\mathrm{pc}}+\frac{\mathrm{K}_{\mathrm{ic}}}{\mathrm{s}}\right) \frac{1}{\mathrm{~L}_{\mathrm{s}} \mathrm{s}}}{1+\left(\mathrm{K}_{\mathrm{pc}}+\frac{\mathrm{K}_{\mathrm{ic}}}{\mathrm{s}}\right) * \frac{1}{\mathrm{~L}_{1} \mathrm{~s}}}=\frac{\mathrm{K}_{\mathrm{pc}} \mathrm{s}+\mathrm{K}_{\mathrm{ic}}}{\mathrm{L}_{1} \mathrm{~s}^{2}+\mathrm{K}_{\mathrm{pc}} \mathrm{s}+\mathrm{K}_{\mathrm{ic}}}
$$

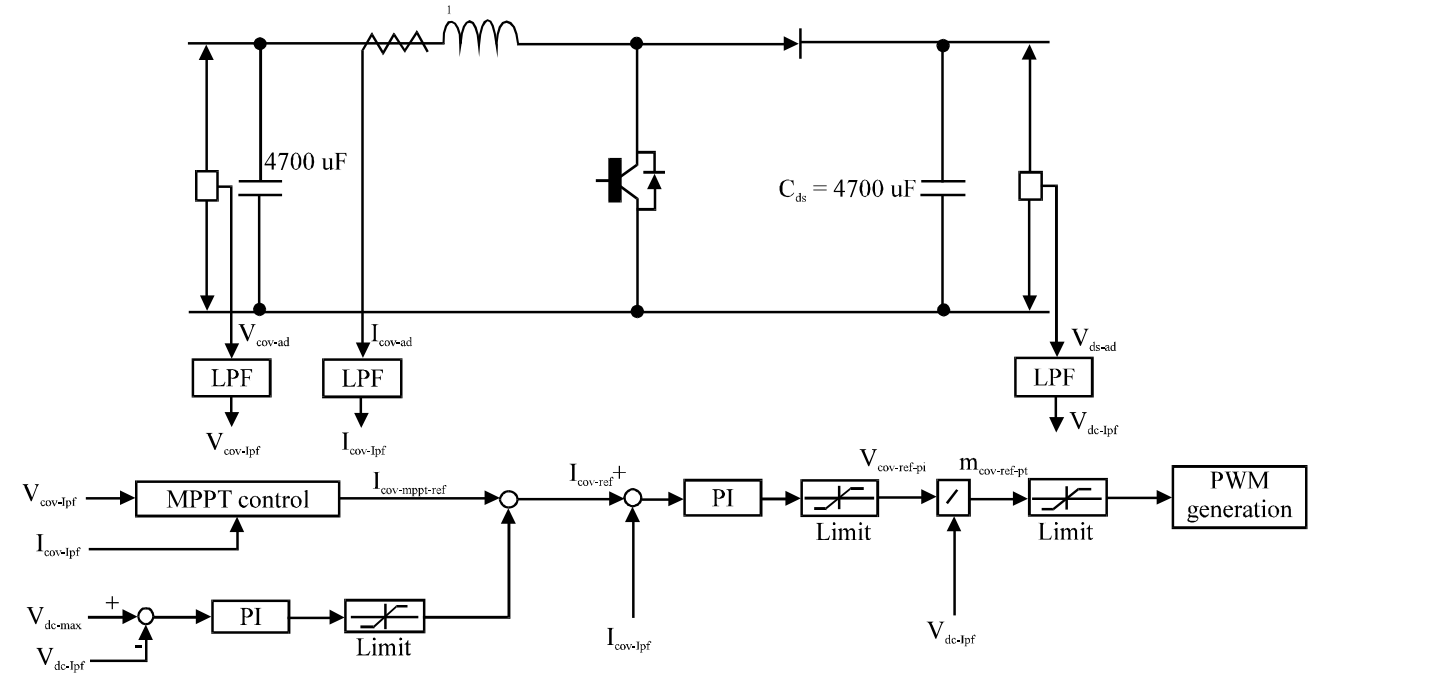

Fig. 3: Converter topology and control strategy for PV power conditioning system 
It is difficult to specify a default set of controller parameters which will work well in all applications. The proportional gain and integral gains can be selected as initial settings and fine-tuned as necessary by trial-and-error in experiments. For the converter current controller, the optimum gains are found in experiments to be $\mathrm{K}_{\mathrm{pc}}=10, \mathrm{~K}_{\mathrm{ic}}=0.6$. The unit-step response for this controller is shown in the Fig. 5.

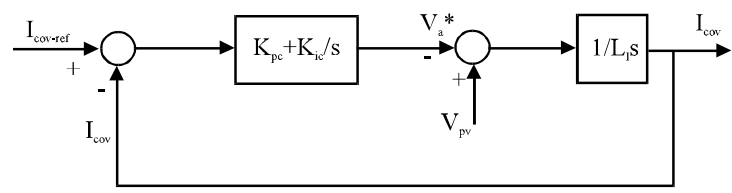

Fig. 4: Block diagram of DC-DC boost converter

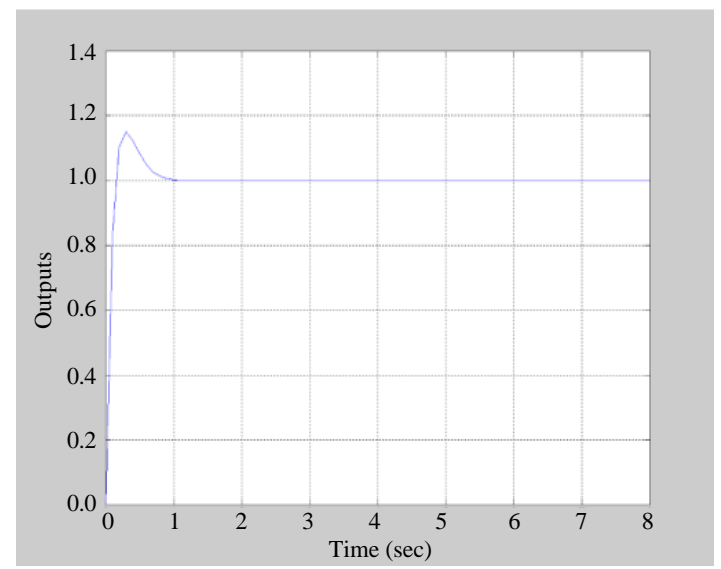

Fig. 5: Unit-step response curves for the converter current controller
Full bridge inverter: As shown in Fig. 6, the inverter controller consists of two control loops, the outer DC-link voltage control loop and the inner current control loop. The function of the outer loop is to control the DC-link voltage to the pre-determined level. The task of the PI controller is to minimize the error between the reference Voltage $V_{d c \_r e f}$ and the measured Voltage $V_{d c}$. The controller output is the inverter reference current $\mathrm{I}_{\text {inv }_{-} \mathrm{p} \text {. } \mathrm{p}_{\text {ref }}}$ which is then controlled by another faster PI controller. The task of this controller is to minimize the error between the reference and measured inverter currents and produce the PWM signal. The PI controllers design for the inverter is explained in the next sub-sections.

DC link controller: Figure 7 shows block diagram of DC-link voltage control where $V_{D_{C} \text { _ef }}$ is reference DC-link voltage and $I_{D C}$ is input current to dc-link Capacitor $C_{D C}$ from solar cell array. The transfer function of the DC-link voltage controller is derived from the block diagram shown in Fig. 7. The error between the reference DC-link Voltage $V_{\text {dc ref }}$ and the sensed DC-link Voltage $V_{D C}$ is fed to the PI voltage controller. Low pass filter is used to mitigate the effect of 2 nd order harmonic voltage which results in performance degradation.

In order to control the DC link voltage to the pre-determined level, DC link voltage controller shown in Fig. 7 is employed and transfer function is like Eq. 5:

$$
\frac{\mathrm{V}_{\mathrm{dc}}}{\mathrm{V}_{\mathrm{dc} \_ \text {ref }}}=\frac{\left(\mathrm{K}_{\mathrm{pdc}}+\frac{\mathrm{K}_{\mathrm{idc}}}{\mathrm{s}}\right)^{*} \frac{1}{\mathrm{C}_{\mathrm{dc}} \mathrm{s}}}{1+\left(\mathrm{K}_{\mathrm{pdc}}+\frac{\mathrm{K}_{\mathrm{idc}}}{\mathrm{s}}\right)^{*} \frac{1}{\mathrm{C}_{\mathrm{dc}} \mathrm{s}}}=\frac{\mathrm{K}_{\mathrm{pdc}} \mathrm{s}+\mathrm{K}_{\mathrm{idc}}}{\mathrm{C}_{\mathrm{dc}} \mathrm{s}^{2}+\mathrm{K}_{\mathrm{pdc}} \mathrm{s}+\mathrm{K}_{\mathrm{idc}}}
$$

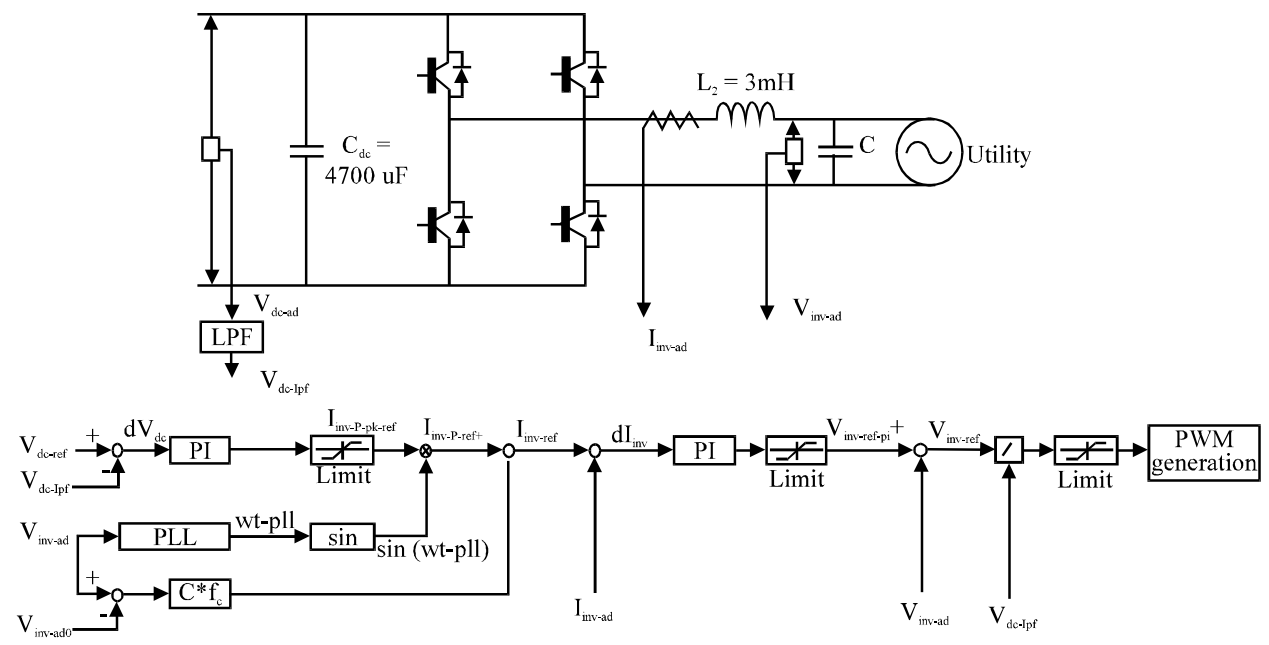

Fig. 6: Inverter topology and control strategy for PV power conditioning system 


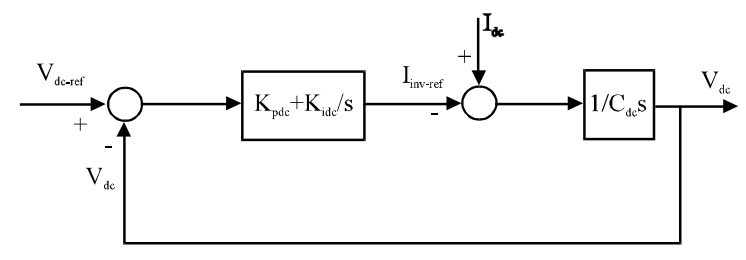

Fig. 7: Block diagram of DC link voltage

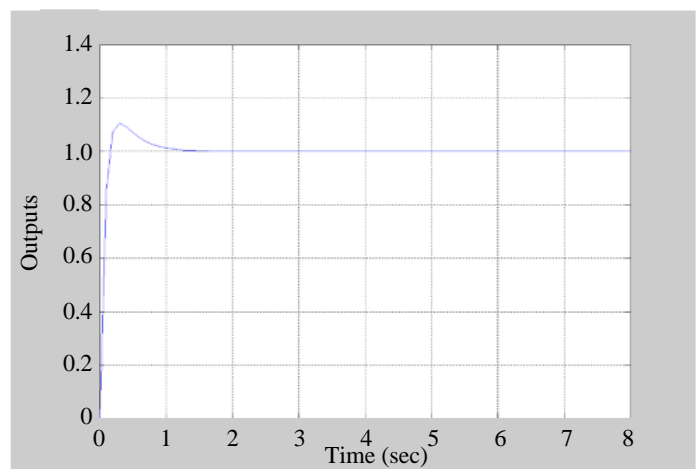

Fig. 8: Unit-Step response curves for the DC-voltage controller

In the same way, the proportional and integral gains are selected and then tuned to obtain a satisfactory performance in experiments by trial and error. The DC link voltage controller gains are $\mathrm{K}_{\mathrm{pdc}}=0.09, \mathrm{~K}_{\mathrm{idc}}=0.0005$. The unit response is shown in Fig. 8.

Grid current controller: The desired amplitude of the inductor current $\mathrm{I}_{\text {inv_ } \mathrm{P}_{-} \mathrm{pk} \_ \text {ref }}$ is generated by the $\mathrm{DC}$ voltage controller, considering the $\mathrm{DC}$ link voltage error $\mathrm{V}_{\mathrm{dc} \_ \text {ref }}-\mathrm{V}_{\mathrm{dc}}$ as the input variable. The reference value of the instantaneous source current $\mathrm{I}_{\text {ing _ef }}$ is generated on the basis of the amplitude $I_{\text {nnv }_{-} \mathrm{P}_{\mathrm{p}} \mathrm{k}_{-} \text {ef }}$ and on the phase angle of the fundamental component of the supply voltage. The measurement of the source current is used to implement the $\mathrm{AC}$ current control loop as shown in Fig. 9. The inverter is controlled on the basis of the instantaneous current error $\Delta \mathrm{I}_{\text {inv }}=\mathrm{I}_{\text {inv_ref }} \mathrm{I}_{\text {inv__ad }}$ through a conventional PI current regulator. By the same way as in Eq. 5, the transfer function could be written as follow:

$$
\frac{\mathrm{I}_{\text {inz_ad }}}{\mathrm{I}_{\text {inv }_{-} \text {ref }}}=\frac{\left(\mathrm{K}_{\mathrm{pi}}+\frac{\mathrm{K}_{\mathrm{iii}}}{\mathrm{s}}\right)^{*} \frac{1}{\mathrm{~L}_{2} \mathrm{~s}}}{1+\left(\mathrm{K}_{\mathrm{pi}}+\frac{\mathrm{K}_{\mathrm{ii}}}{\mathrm{s}}\right)^{*} \frac{1}{\mathrm{~L}_{2} \mathrm{~s}}}=\frac{\mathrm{K}_{\mathrm{pis}} \mathrm{s}+\mathrm{K}_{\mathrm{ii}}}{\mathrm{L}_{2} \mathrm{~s}^{2}+\mathrm{K}_{\mathrm{pi}} \mathrm{s}+\mathrm{K}_{\mathrm{ii}}}
$$

Similarly, the inverter current controller gains are $\mathrm{K}_{\mathrm{pi}}=25, \mathrm{~K}_{\mathrm{ii}}=1.3$. The unit response is shown in Fig. 10.

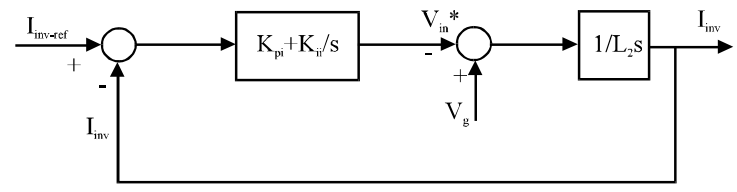

Fig. 9: Block diagram of grid side current controller

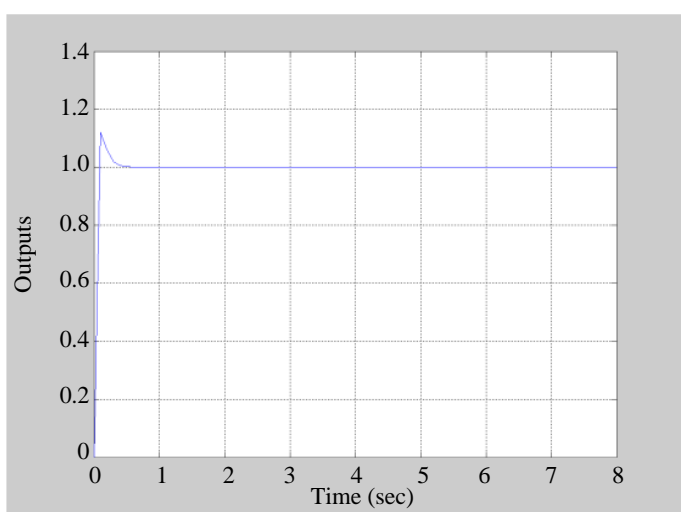

Fig. 10: Unit-step response curves for the inverter current controller

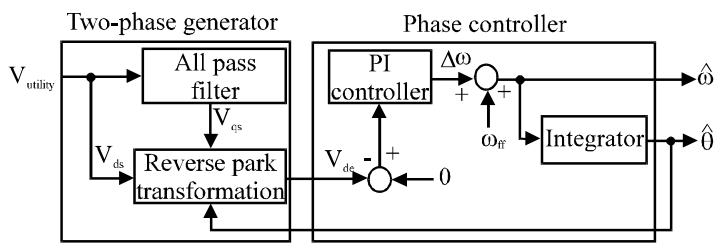

Fig. 11: Structure of PLL for single phase syste

Phase locked loop: In order to use reference frame theory for simple control, the single-phase voltage should have virtual two-phase voltage with $90^{\circ}$ out of phase (Yu, 2018). Based on this concept, the PLL for single phase system consists of two stages: one is two-phase generator and the other is phase controller as Fig. 11:

$$
\begin{gathered}
\left(\begin{array}{c}
\mathrm{V}_{\mathrm{de}} \\
\mathrm{V}_{\mathrm{qe}}
\end{array}\right)=\left(\begin{array}{cc}
\cos \hat{\theta} & \sin \hat{\theta} \\
-\sin \hat{\theta} & \cos \hat{\theta}
\end{array}\right) \cdot\left(\begin{array}{c}
\mathrm{V}_{\mathrm{ds}} \\
\mathrm{V}_{\mathrm{qs}}
\end{array}\right)=\left(\begin{array}{c}
\mathrm{V}_{\mathrm{ds}} \cdot \cos \hat{\theta}+\mathrm{V}_{\mathrm{qs}} \cdot \sin \hat{\theta} \\
-\mathrm{V}_{\mathrm{ds}} \cdot \sin \hat{\theta}+\mathrm{V}_{\mathrm{qs}} \cdot \cos \hat{\theta}
\end{array}\right) \\
\mathrm{V}_{\mathrm{de}}=\mathrm{V}_{\mathrm{ds}} \cdot \cos \hat{\theta}+\mathrm{V}_{\mathrm{qs}} \cdot \sin \hat{\theta}=\mathrm{V}_{\mathrm{m}} \sin \theta \cdot \cos \hat{\theta}- \\
\mathrm{V}_{\mathrm{m}} \cos \theta \cdot \sin \hat{\theta}=\mathrm{V}_{\mathrm{m}} \sin (\theta-\hat{\theta})
\end{gathered}
$$

With the grid voltage $\mathrm{V}_{\mathrm{ds}}$ and the calculated lagging $90^{\circ}$ out of phase voltage $V_{\mathrm{gs}}$, the active and reactive component in the reference frame can be drawn by 
applying the reverse Park transformation as Eq. 7. As shown in Eq. 7 and 8, the rotating reference frame is based on the estimated phase angle $\hat{\theta}$ and the estimated frequency $\hat{\omega}$ (Fig. 12).

As shown in Eq. 8, the reactive voltage component $\mathrm{V}_{\text {de }}$ should be controlled to be zero for unity power factor for the estimated phase angle $\hat{\theta}$ to be equal to the real phase angle $\theta$. In order to control the estimated phase angle error, $\Delta \omega$ is obtained using PI controller. The $\Delta \omega$ is added to the initial value $\omega_{\text {ff }}$ to achieve the estimated frequency $\hat{\omega}$ and the estimated phase angle $\hat{\theta}$.

\section{RESULTS AND DISCUSSION}

Based on PV inverter hardware and software configuration, the $3 \mathrm{~kW} \mathrm{PV} \mathrm{inverter} \mathrm{is} \mathrm{tested} \mathrm{for} \mathrm{its} \mathrm{normal}$ grid connected operation. The high precision PV array simulator and grid simulator are utilized for $3 \mathrm{~kW} \mathrm{PV}$ inverter testing. The test items of the implemented

(a)

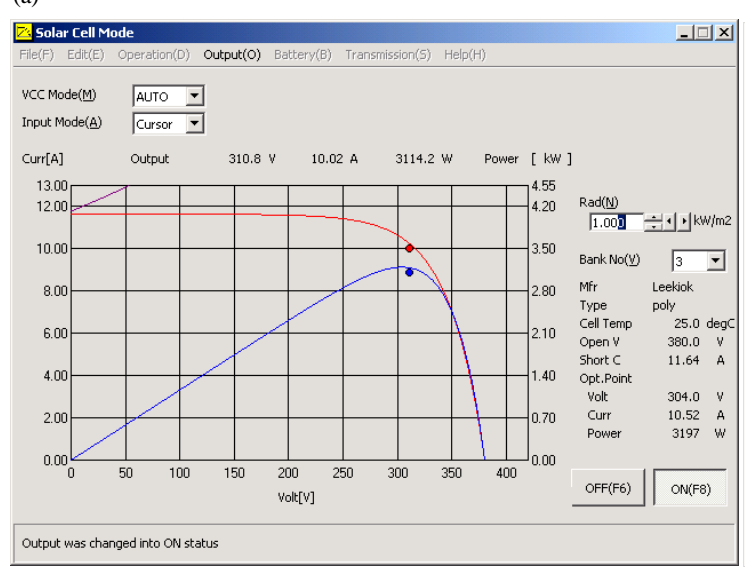

(c)

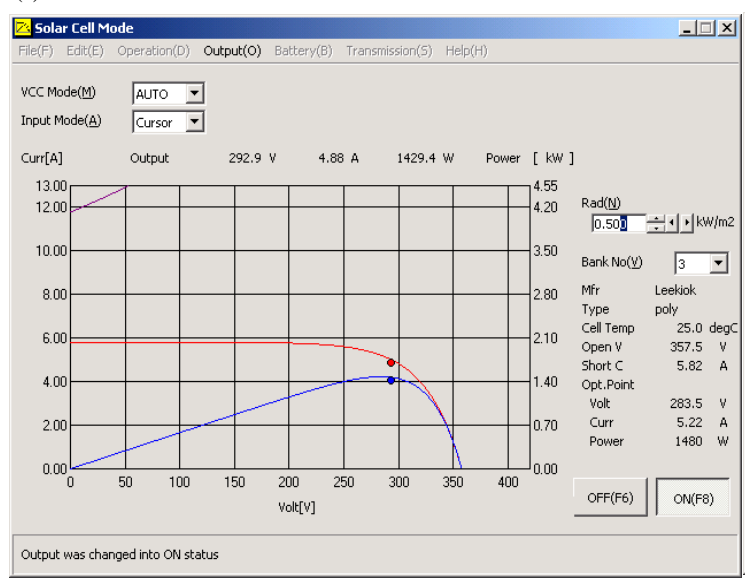

inverter are as follows: firstly, maximum power tracking function for boost converter and then $\mathrm{AC}$ power quality of PV inverter output.

For $3 \mathrm{~kW} \mathrm{PV}$ inverter testing, the PV simulator is set to $3197 \mathrm{~W}$ power capacity as Table 1 . The instant maximum power tracking efficiency under four different irradiance conditions $100,75,50$ and $25 \%$ are measured $97.41,97.03,96.58$ and $96.01 \%$, respectively as shown in Fig. 12. The MPPT performance is high enough over $95 \%$ which requires in Korean PV inverter standard.

When the inverter output power is the nominal power $3 \mathrm{~kW}$ as shown in Fig. 13, the total harmonic distortion of inverter current is $0.94 \%$ and the power factor is 0.9995 which meets the Korean PV inverter standard.

Table 1: PV array condition for MPPT test

\begin{tabular}{ll}
\hline Items & Values \\
\hline PV array capacity & $3197(\mathrm{~W})$ at $25^{\circ} \mathrm{C}\left(\mathrm{V}_{\mathrm{mp}}=304 \mathrm{~V}, \mathrm{I}_{\mathrm{mp}}=10.52 \mathrm{~A}\right)$ \\
Open PV voltage & $380(\mathrm{~V})$ \\
Short PV current & $11.64(\mathrm{~A})$ \\
\hline
\end{tabular}

(b)

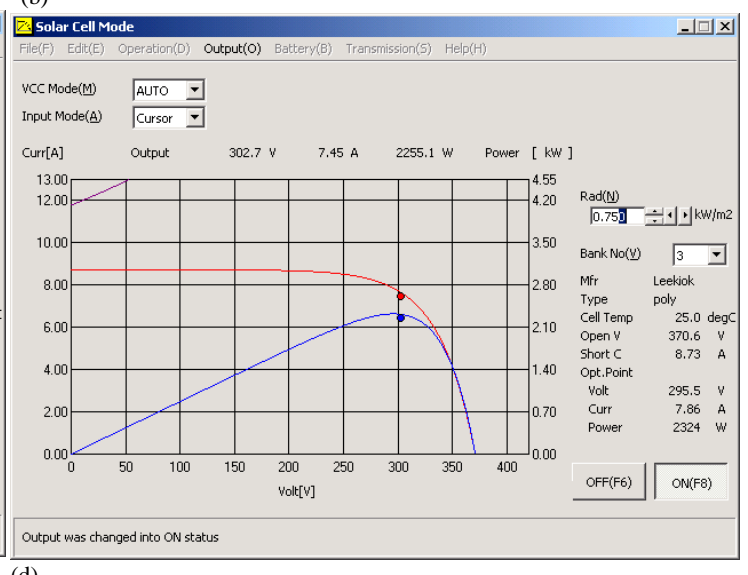

(d)

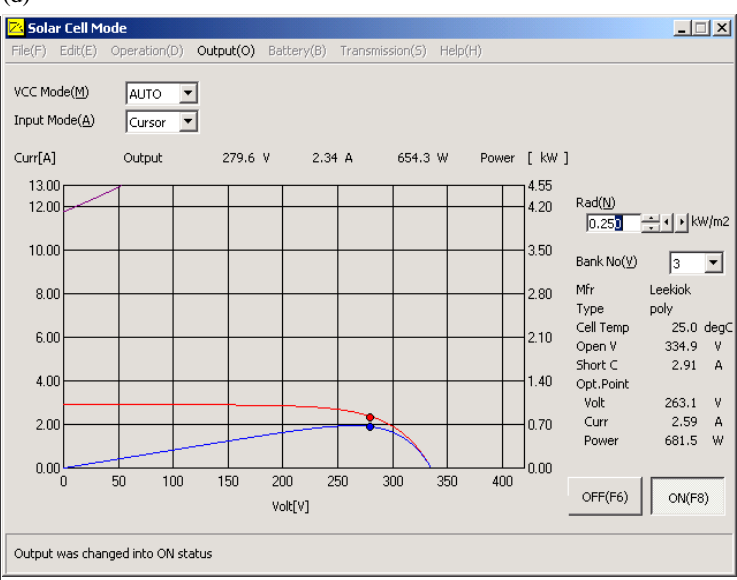

Fig. 12: MPPT performance evaluation of the implemented single-phase PV inverter: a) Under $100 \%$ irradiance; b) Under $75 \%$ irradiance; c) Under 50\% irradiance and d) Under 25\% irradiance 


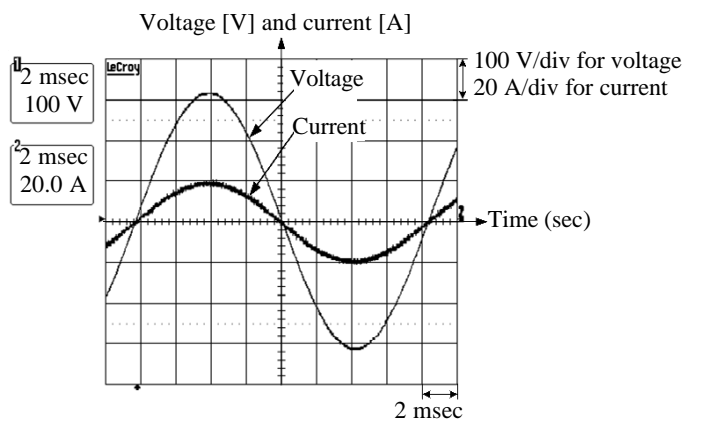

Fig. 13: Inverter output voltage and current waveforms

\section{CONCLUSION}

As a single-phase PV inverter, the design of a transformer-less PV inverter consisted of a boost converter, followed by a Voltage-Source Inverter (VSI) was presented in this study. The boost converter provided Maximum Power Point Tracking (MPPT) function and the voltage source inverter made a stable DC link voltage from an unregulated output voltage of PV array in addition to DC/AC inverting. With these control targets, the full control block diagrams were presented. Furthermore, the PLL technique as a key control technique for single phase inverter was presented by using the all pass filter. The instant maximum power tracking efficiency under four different irradiances 100, 75, 50 and $25 \%$ were measured $97.41,97.03,96.58$ and $96.01 \%$, respectively. When the inverter generated the nominal power $3 \mathrm{~kW}$, the total harmonic distortion of inverter current was $0.94 \%$ and the power quality is 0.9995 . According the presented design methodology of $3 \mathrm{~kW}$ class PV inverter has high performance to the Korean standard requirements which could be extended to higher power PV application.

\section{ACKNOWLEDGEMENTS}

This research was supported by the National Research Foundation of Korea (NRF) grant funded by the Korea government (MSIP) [grant number 2016R1C1B1007001].

\section{REFERENCES}

Deshpande, S. and N.R. Bhasme, 2017. A review of topologies of inverter for grid connected PV systems. Proceedings of the 2017 International Conference Innovations in Power and Advanced Computing Technologies (I-PACT), April 21-22, 2017, IEEE, Vellore, India, ISBN:978-1-5090-5683-5, pp: 1-6.
Kafle, Y.R., G.E. Town, X. Guochun and S. Gautam, 2017. Performance comparison of single-phase transformerless PV inverter systems. Proceedings of the 2017 IEEE International Conference on Applied Power Electronics Conference and Exposition (APEC), March 26-30, 201 7, IEEE, Tampa, Florida, USA., ISBN: 978-1-5090-5367-4, pp: 3589-3593.

Kjaer, S.B., J.K. Pedersen and F. Blaabjerg, 2005. A review of single-phase grid-connected inverters for photovoltaic modules. IEEE Trans. Ind. Appl., 41: 1292-1306.

Li, W., Y. Gu, H. Luo, W. Cui and X. He et al., 2015. Topology review and derivation methodology of single-phase transformerless photovoltaic inverters for leakage current suppression. IEEE. Trans. Ind. Electron., 62: 4537-4551.

Noor, S.M., A.M. Omar, N.N. Mahzan and I.R. Ibrahim, 2013. A review of single-phase single stage inverter topologies for photovoltaic system. Proceedings of the 2013 IEEE 4th International Conference on Control and System Graduate Research Colloquium (ICSGRC), August 19-20, 2013, IEEE, Shah Alam, Malaysia, pp: 69-74.

Papanikolaou, N., A. Kyritsis, M. Loupis, C. Tzotzos and E. Zoga, 2015. Design considerations for single-phase line frequency transformers applied at photovoltaic systems. IEEE. Power Energy Technol. Syst. J., 2: 82-93.

Tian, F., H. Al-Atrash, R. Kersten, C. Scholl and K. Siri et al., 2006. A single-staged PV array-based high-frequency link inverter design with grid connection. Proceedings of the 2006 21 st Annual IEEE Conference and Exposition on Applied Power Electronics (APEC'06), March 19-23, 2006, IEEE, Dallas, Texas, USA., pp: 1-4.

Variath, R.C., M.A. Andersen, O.N. Nielsen and A. Hyldgard, 2010. A review of module inverter topologies suitable for photovoltaic systems. Proceedings of the 2010 International Conference on IPEC, October 27-29, 2010, IEEE, Singapore, Singapore., ISBN: 978-1-4244-7399-1, pp: $310-316$.

Vithayasrichareon, P., G. Mills and I.F. MacGill, 2015. Mpact of electric vehicles and solar PV on future generation portfolio investment. IEEE. Trans. Sustainable Energy, 6: 899-908.

Xue, Y., L. Chang, S.B. Kjaer, J. Bordonau and T. Shimizu, 2004. Topologies of single-phase inverters for small distributed power generators: An overview. IEEE Trans. Power Electron., 19: 1305-1314.

$\mathrm{Yu}$, B., 2018. An improved frequency measurement method from the digital PLL structure for single-phase grid-connected PV applications. Electron., 7: 1-11. 